\title{
REVISÃO DA PRODUÇÃO CIENTÍFICA BRASILEIRA: A FORMAÇÃO CONTINUADA DOS PROFISSIONAIS QUE ESTÃO NA CRECHE
}

\author{
Fabiana Cristina Frigieri Vitta ${ }^{1}$, Carla Francielly Martini Novaes ${ }^{2}$, Girlene Albuquerque Cruz $^{3}$ \\ ${ }^{1}$ Doutor em Educação Especial pela Universidade Federal de São Carlos - UFScar. Docente no Departamento de Educação \\ Especial da Universidade Estadual Paulista - UNESP, Marília, SP e do Programa Pós-Graduação em Educação Escolar da \\ UNESP de Araraquara. E-mail: fabianavitta@gmail.com \\ ${ }^{2}$ Mestranda da Pós-Graduação em Educação Escolar da Faculdade de Ciências e Letras da Universidade Estadual Paulista - \\ UNESP, Araraquara \\ ${ }^{3}$ Mestranda da Pós-Graduação em Educação Escolar da Faculdade de Ciências e Letras da Universidade Estadual Paulista - \\ UNESP, Araraquara
}

\section{RESUMO}

Esse ensaio objetiva olhar para a problemática da formação continuada dos profissionais da creche. Para endossar a discussão, foram utilizados dados provenientes da base de dados Biblioteca Digital Brasileira de Teses e Dissertações (BDTD) sobre o tema, no período de 1997 a 2017, ou seja, nos últimos 20 anos após a publicação da Lei de Diretrizes e Bases da Educação Nacional. Verificamos que as pesquisas desenvolvidas no Brasil versam sobre os temas políticas públicas de formação continuada; práticas e saberes dos profissionais; atuação do coordenador pedagógico na formação continuada; e programas de formação continuada. Os trabalhos evidenciam a importância do aprimoramento das práticas de formação continuada junto aos professores e profissionais na creche permitindo que teoria e prática se identifiquem na constituição de um corpo de conhecimento que beneficie as crianças dessa faixa etária. Embora constatemos certo avanço na compreensão desta etapa da educação básica, verificamos a necessidade de se valorizar a formação dos profissionais para práticas mais embasadas.

Palavras-chave: Educação Infantil. Formação Continuada. Creche.

\section{A REVIEW OF BRAZILIAN SCIENTIFIC PRODUCTION: THE CONTINUED TRAINING OF THE PROFESSIONALS WHO ARE IN THE NURSERY}

\begin{abstract}
This essay aims to look at the problem of the continuous training of day care professionals. To endorse the discussion, data from the Brazilian Digital Library of Theses and Dissertations (BDTD) database were used on the subject from 1997 to 2017, that is, in the last 20 years after the publication of the Law of Guidelines and Bases of National Education. We verified that the researches developed in Brazil deal with the public policy themes of continuing education; practices and knowledge of professionals; performance of the pedagogical coordinator in continuing education; and continuing education programs. The studies highlight the importance of improving continuing education practices among teachers and professionals in the day care center, allowing theory and practice to be identified in the constitution of a body of knowledge that benefits the children of this age group. Although we can see some progress in understanding this stage of basic education, we verified the need to value the training of professionals for more based practices.
\end{abstract}

Keywords: Early Childhood Education. Continuing Education. Day care.

A educação infantil, primeira etapa da educação básica, está organizada em creche (para crianças de zero a três anos) e pré-escola (para crianças de quatro e cinco anos ${ }^{1}$ ), passando a ser

1 A lei no no 12.796, de 2013 (disponível em

<http://www.planalto.gov.br/ccivil_03/_ato2011-

Colloquium Humanarum, Presidente Prudente, v. 15, n. 3, p.94-105 jul/set 2018. DOI: 10.5747/ch.2018.v15.n3.h376 considerada parte integrante do sistema educacional brasileiro a partir da promulgação da

2014/2013/lei/I12796.htm>, estabelece essa faixa etária, devendo ser considerado que o ensino fundamental inicia-se aos seis anos de idade, de acordo com a Lei no 11.274 de 2006, disponível em <http://www.planalto.gov.br/ccivil_03/_Ato2004-

2006/2006/Lei/L11274.htm 
Lei de Diretrizes e Bases da Educação Nacional LDBEN (Lei 9.394/96). Essa lei veio ao encontro da Constituição Federal de 1988, que assinala em seu conteúdo que a educação para as crianças de zero a seis anos de idade deveria ser garantida pelo poder público.

Esses documentos são importantes por destacarem o dever do estado com a educação e não com a assistência social, pois até aquele momento, esse atendimento era mantido pelas assistências sociais dos municípios, filantropias empresariais, instituições confessionais e particulares, organizações não governamentais e outras iniciativas do genêro. Sobre isso, Kramer (1992, p. 61) afirma que "[...] associações religiosas e organizações leigas, bem como médicos, educadores e leigos eram solicitados a realizar juntos com o setor público a proteção e o atendimento a infância, com a direção e alguma subvenção deste último".

A preocupação desde o início do atendimento à primeira infância em espaços não domésticos se pautava em garantir um local para que os filhos de mães trabalhadoras fossem cuidados durante as jornadas de trabalho, ou seja, a creche foi vista primeiramente como uma solução para organização da sociedade naquele momento histórico, no qual o mundo do trabalho passava a receber a mão de obra feminina e as famílias passaram a se organizar de forma diferente da tradicional.

A creche não foi pensada como um direito da criança, mas como uma necessidade social. Esse atendimento era "[...] moldado em políticas assistencialistas, marcadas principalmente por iniciativas de entidades privadas e filantrópicas. Representava não direito das crianças, mas um favor aos pais pobres" (BOLDRIN, 2007, p. 27, grifos do autor).

$\mathrm{Na}$ atualidade, o direito da criança por um atendimento educacional de qualidade converge com o direito da mulher em ter um local seguro e que ofereça educação e cuidado aos seus filhos enquanto ela trabalha fora do ambiente doméstico ou não. A partir desse entendimento destacamos que a concepção que a sociedade tem de mulher e de criança sempre influenciou o atendimento educacional na primeira infância, com certo receio sobre a legitimidade dessa fase educacional e a necessidade de "substituir" a mãe, tanto que ao longo da história os profissionais que atuam com as crianças pequenas receberam nomes diversos como: pajem, berçarista, cuidadora, agente de desenvolvimento infantil, monitora, entre outros.
Ainda que haja um movimento para o entendimento dessa fase como parte do sistema educacional, como ressaltam Bahia e Mociutti (2017), ela ainda está muito atrelada às condições sociais de uma camada da educação, fato que garante seu caráter assistencialista.

A rotina da maior parte
dos berçários se
desenvolve baseada no
papel de cuidar, pela
própria especificidade da
faixa etária, ou seja, a
criança pequena é vista
como um ser que deve ser
cercado de cuidados de
modo a promover um
desenvolvimento sadio.
Esse fato está
diretamente relacionado
ao modelo de creche
implantado no Brasil, com
características
assistencialistas,
ainda hoje objetiva
atender a uma parcela
carente da sociedade -
mães que não têm
condições sócio-
econômicas para ficar o
dia todo com a criança
(VITTA; EMMEL, 2004, p.
187).

A educação das crianças pequenas está envolta por várias questões que vão desde os aspectos legais e históricos sobre a necessidade dessa etapa da educação básica até a questão da formação continuada dos profissionais. Esse ensaio objetiva olhar para essa problemática formação continuada dos profissionais da creche a partir das pesquisas realizadas nos programas de pós-graduação, nos últimos 20 anos.

Algumas questões que despontam referem-se a quais circunstâncias envolvem a formação dos professores nas instituições educativas, estando essa discussão diretamente relacionada à necessidade de aprimorar a qualidade dos serviços educacionais ofertados a essa faixa etária.

Ao tratarmos de formação de professores de creche, especialmente de berçário, verificamos uma discussão incipiente, já que historicamente esse atendimento foi mais relacionado ao cuidado, não sendo exigida formação pedagógica para a função. Eram pontuais e bastante direcionadas às atividades de cuidado, como questões sobre higienização de utensílios de 
alimentação e banho, formas de organizar essas atividades de modo a melhorar o fluxo de trabalho, dentre outros. Esse conhecimento, embora importante para essa fase da educação por garantir um cuidado adequado, não garante a educação e aprendizagem próprias para a faixa etária.

Os documentos oficiais buscaram fazer essa discussão. No artigo 62, a LDB indica que os docentes, para trabalhar com toda a educação básica, deverão ter uma formação específica:

Art. 62. A formação de docentes para atuar na educação básica far-se-á em nível superior, em curso de licenciatura plena, admitida, como formação mínima para o exercício do magistério na educação infantil e nos cinco primeiros anos do ensino fundamental, a oferecida em nível médio, na modalidade normal.

§ 1으 A União, o Distrito Federal, os Estados e os Municípios, em regime de colaboração, deverão promover a formação inicial, a continuada e a capacitação dos profissionais de magistério (BRASIL, 1996, p. 62-63).

Com essa nova realidade, os municípios, responsáveis por essa fase da educação, tiveram que se adequar promovendo formação para os profissionais leigos, bem como exigindo titulação dos novos contratados, além de passar a promover a formação continuada em serviço, criando mecanismos e espaços para estudo e discussão sobre as necessidades formativas e pedagógicas enfrentadas no cotidiano.

O Plano Nacional de Educação (PNE), em sua versão de 2001, faz um diagnóstico da educação infantil no início da implantação da LDBEN e ressalta a falta de informações sobre a fase da creche naquela época. Destaca dentre os objetivos e metas para a educação infantil, a necessidade de formação dos profissionais, com a colaboração da União, Estados e Municípios, estabelecendo tanto a formação dos dirigentes como dos professores desa fase educacional, em nível superior (BRASIL, 2001).

$\mathrm{O}$ artigo publicado por Campos, Fullgraf e Wiggers (2006, p. 90) ao finalizar o prazo para adequação da realidade brasileira às normas da LDBEN mostra claramente a dificuldade para mudanças nesse quadro.

Essa exigência vem sendo aceita com alguma dificuldade pelos sistemas de educação, especialmente no caso das creches. Ao mesmo tempo em que, em muitos estados e prefeituras, foram organizados cursos de formação para os educadores leigos que já se encontravam trabalhando nessas instituições, muitas prefeituras e entidades têm contestado a exigência e buscado subterfúgios, por exemplo, contratando educadores como se desempenhassem atividades de limpeza, para fugir ao requisito de formação prévia.

O PNE de 2014 tem como sua primeira meta a educação infantil e a necessidade de universalizar o atendimento na pré-escola e a ampliação em creche. Coloca como uma das estratégias a formação profissional inicial e continuada, progressivamente em nível superior e a

[...] articulação entre pós-
graduação, núcleos de
pesquisa e cursos de
formação para profissionais
da educação, de modo a
garantir a elaboração de
currículos e propostas
pedagógicas que incorporem
os avanços de pesquisas
ligadas ao processo de
ensino-aprendizagem e às
teorias educacionais no
atendimento da população
de 0 (zero) a 5 (cinco) anos
(BRASIL, 2014, p. 4).

A formação tem maior relevância após a publicação da Base Nacional Comum Curricular (BNCC), que traça objetivos específicos para a educação das crianças em creches e pré-escolas. Vitta, Cruz e Scarlassara (2018, p.70) em análise da relação entre BNCC e berçário comentam que 
maior que documentos anteriores à educação dos bebês, apresentando objetivos de aprendizagem que vão além dos cuidados, porém ainda pouco instrumentais no que tange a metodologia aplicáveis para se atingir a indissociabilidade de cuidado e educação, ficando esse papel a cargo das instituições e profissionais.

Ou seja, a formação do profissional ganha destaque, pois ele tem que estar preparado para analisar esses documentos que regem a educação infantil e colocá-lo em prática, garantindo a qualidade dessa fase. Pensando na necessária articulação entre as universidades e a capacitação dos professores, nos questionamos: o que os estudos produzidos falam sobre a formação continuada e a creche?

A partir dessa indagação, buscamos na Biblioteca Digital Brasileira de Teses e Dissertações (BDTD), que armazena as teses e dissertações produzidas nos programas de pósgraduação brasileiros, como tem sido tratada a formação continuada na creche. Para tal, usamos os descritores: formação continuada e creche, delimitando o período de 1997, ano imediato à promulgação da Lei de Diretrizes e Bases da Educação Nacional, a 2017, ou seja, 20 anos da produção bibliográfica, após esse importante marco da educação brasileira. Numa primeira busca, encontramos 543 documentos.

A leitura dos títulos e resumos permitiram explorar o material para identificar se a obra relacionava-se aos nossos objetivos, pois embora falassem sobre formação, nem sempre direcionava-se à continuada e muitos focavam a educação infantil de modo geral ou enfatizavam a pré-escola. Em alguns casos, precisamos entrar no texto completo e usarmos o sistema de busca dos documentos em pdf para verificar se contemplavam os descritores creche, crianças pequenas, além de procurarmos referências à faixa etária. Eliminamos aqueles que não focavam a creche e suas características específicas, não atendendo por não atenderem à nossa proposta de darmos atenção à formação continuada e a fase educacional de zero a três anos, com as suas particularidades.

Após essa etapa selecionamos 32 trabalhos para serem analisados minuciosamente por tratarem especificamente da formação continuada dos profissionais da creche, sendo oito teses e 24 dissertações. Todas foram organizadas em planilhas do Excel, contemplando: título do texto, tipo (dissertação ou tese), ano de publicação, palavras-chave, resumo, autores, programa e local.

A seguir apresentamos o Quadro $1 \mathrm{com}$ o título do texto, ano e autor, iniciado com um número que usamos para identificá-los e uma letra que representa se é tese $(T)$ ou dissertação (D), sendo que os dados completos podem ser encontrados nas referências desse ensaio. 
Quadro 1. Apresentação dos textos encontrados pelas autoras, ano de publicação e autoria.

\begin{tabular}{|c|c|c|}
\hline Titulo do documento & Ano & Autores \\
\hline $\begin{array}{l}1 \text { - D. Contribuições da formação continuada em service para a } \\
\text { construção da identidade do profissional de educação infantil }\end{array}$ & 2003 & Santos, M. O. V \\
\hline $\begin{array}{l}2 \text { - D. A formação continuada do professor de educação infantil: } \\
\text { um estudo dos cursos de formação por SME e FABES no } \\
\text { município de São Paulo 1989-1996 }\end{array}$ & 2005 & Santos, H. R. S. \\
\hline $\begin{array}{l}3 \text { - D. A influencia de um programa de formação continuada com } \\
\text { vistas a implantação do PROEPRE no desempenho de } \\
\text { profissionais de creche assistenciais }\end{array}$ & 2006 & Costa, D. P. L. P. \\
\hline $\begin{array}{l}4 \text { - T. A especialização como espaço de formação continuada do } \\
\text { professor de educação infantil em Goiás }\end{array}$ & 2007 & Boldrin, L. C. F. \\
\hline $\begin{array}{l}5 \text { - D. Processos formativos constituídos no interior das } \\
\text { instituições de educação infantil }\end{array}$ & 2007 & Zapelini, C. A. E. \\
\hline $\begin{array}{l}6 \text { - D. Pesquisa-ação-participativa e a temática sócio- ambiental } \\
\text { no processo de formação continuada de } \\
\text { professoras da educação infantil }\end{array}$ & 2006 & Sato, T. A. \\
\hline $\begin{array}{l}7 \text { - D. Formação contínua em serviço: um estudo com os } \\
\text { profissionais dos centros de educação infantil }\end{array}$ & 2007 & Bueno, M. C. S. \\
\hline \begin{tabular}{|l}
8 - T. Curso de extensão universitária PROEPE: \\
contribuição para formação de professores de creche
\end{tabular} & 2009 & Borges, R. R. \\
\hline $\begin{array}{l}9 \text { - D. Escrever sobre a própria prática: desafios na formação do } \\
\text { professor da primeira infância }\end{array}$ & 2009 & Zurawski, M. P. V. \\
\hline $\begin{array}{l}10 \text { - D. Educação infantil na perspectiva das relações étnico- } \\
\text { raciais: relato de duas experiências de formação continuada de } \\
\text { professores no município de Santo André }\end{array}$ & 2009 & Saraiva, C. F. \\
\hline $\begin{array}{l}11 \text { - D. O descompasso entre as políticas públicas de formação do } \\
\text { professor de educação infantil e a prática cotidiana do município } \\
\text { de Bayeux na Paraíba }\end{array}$ & 2009 & Santos, M. C. \\
\hline $\begin{array}{l}12 \text { - D. Educação para a vigilância do desenvolvimento infantil: } \\
\text { formação virtual e presencial para educadores de creche }\end{array}$ & 2009 & Neófiti, C. \\
\hline $\begin{array}{l}13 \text { - D. O coordenador pedagógico e o seu papel na formação } \\
\text { continuada em serviço do professor de educação infantil (creche) }\end{array}$ & 2010 & Zumpano, V. A. A. \\
\hline $\begin{array}{l}14 \text { - T. Impacto do treinamento de educadores de berçários de } \\
\text { creches em seus conhecimentos e práticas sobre alimentação }\end{array}$ & 2010 & Oliveira, M. N. \\
\hline $\begin{array}{l}15 \text { - D. Formação continuada para professores de } \\
\text { Educação Infantil: concepções de profissionais da rede municipal } \\
\text { de ensino de Fortaleza. }\end{array}$ & 2011 & Guedes, E. A. \\
\hline $\begin{array}{l}16 \text { - T. Formação em contexto na educação infantil: uma parceria } \\
\text { em busca da melhoria da qualidade de uma crèche municipal de } \\
\text { Fortaleza }\end{array}$ & 2013 & Lima, A. E. O. \\
\hline $\begin{array}{l}17 \text { - D. A formação de professoras em uma creche universitária: o } \\
\text { papel da documentação no processo formativo }\end{array}$ & 2013 & Vieira, F. R. \\
\hline $\begin{array}{l}18 \text { - D. A formação continuada na perspectiva das coordenadoras } \\
\text { pedagógicas de creches municipais de Fortaleza }\end{array}$ & 2013 & Leite, M. I. M. \\
\hline $\begin{array}{l}19 \text { - D. Professoras de crianças de } 0 \text { a } 3 \text { anos: dialogando sobre } \\
\text { seus percursos formativos }\end{array}$ & 2013 & Bragatto, A. C. \\
\hline
\end{tabular}


20 - T. Dubabi Du: uma proposta de formação e intervenção musical na creche

21 - D. Práticas educativas entre pares: estudo do trabalho diário de professoras em um centro de educação infantile e paulistano

22 - T. A formação continuada das professoras da educação infantil em Anápolis-GO

23 - D. O coordenador pedagógico e a formação continuada dos profissionais de creche: possibilidades e desafios

24 - D. Sentidos que emergem do/circulam no trabalho docente na Educação Infantil

25 - D. A relação entre a formação continuada e as práticas pedagógicas na perspectiva de professoras da educação infantil em um Município do Ceará

26 - D. Uma experiência de formação continuada: o papel do coordenador pedagógico e do registro reflexivo na formação de professores de Educação Infantil

27 - D. Os espaços lúdicos como elementos formadores em uma creche do município de Santo André

28 - D. Planejamento e rotina na creche: atuação da equipe gestora e de professoras para mudanças nas práticas educacionais

29 - D. A atuação de uma coordenadora pedagógica no Centro de Educação Infantil da SME/SP: cantos e saberes que encantam

30 - D. Formação Continuada na Creche: Fatos e Fotos que Revelam um Percurso Formativo

31 - T. Afetividade na creche: construção colaborativa de saberes e práticas docentes a partir da teoria Walloniana

32 -T. Formação continuada numa perspectiva da educação para a inteireza: uma necessidade do professor de creche

Fonte: dados obtidos na Biblioteca Digital Brasileira de Teses e Dissertações (BDTD).

No período de 1997 a 2003 não encontramos trabalhos específicos relativos a temática em questão. Verificamos uma preocupação maior a partir de 2003, talvez relacionada à demanda própria dos acontecimentos práticos, ou seja, segundo a LDBEN os municípios tinham 10 anos para organizar a educação infantil em suas secretarias de educação, tirando-os da Assistência Social, fato que com certeza, chamou a atenção de pesquisadores, pois configurou-se uma mudança importante no cenário do atendimento à infância. Dessa forma, a produção científica da BDTD aponta para a creche como um ambiente primariamente de cuidados, de forma que fica evidente que o cuidar e o educar ainda estão dissociados, contrariando o que prevê a legislação vigente. Defende-se, em todas as pesquisas analisadas, uma formação de professores que qualifique este profissional para trabalhar com as crianças pequenas de maneira integral, sendo esse o principal foco do atendimento da creche.

Para facilitar o entendimento de como esses trabalhos contribuem para a discussão da formação continuada para os profissionais da creche, os organizamos em quatro temas: políticas públicas voltadas para a formação continuada dos educadores de creche, as práticas e saberes dos profissionais, função do coordenador pedagógico na formação continuada e programas de formação continuada, tratando seus alcances e limitações.

Nas pesquisas que investigaram as políticas públicas de formação continuada, Santos (2005), Zapelini (2007), Santos (2009) e Oliveira (2014) mostraram que ainda existe maior preocupação com aquela destinada aos profissionais da pré-escola (mais relacionada a escolarização) em detrimento à formação de profissionais que atendem a creche (mais relacionada aos cuidados). Santos (2005) destaca que a formação continuada e a construção da 
identidade sofre permanente descontinuidade a cada mudança de gestão municipal. Oliveira (2014, p. 197) argumenta que:

a formação continuada
por si só não conseguirá
cumprir ou alcançar
sucesso no que prescreve
as políticas públicas
educacionais, seja no que
se refere à qualidade da
educação, seja na
efetivação do processo de
profissionalizaçãor e
valorização dos agentes
sociais do campo. Esses
são fatores que devem
ser pensados
executados em conjunto
ou perderão a força
individualmente: a sua
força está na sua
coletividade.

Verificamos aqui a importância da continuidade de uma política de formação independente de partidos políticos, ou seja, de um programa de capacitação que envolva a comunidade e que persista para além de períodos de gestão, seja municipal, estadual ou federal. Essa tem sido uma crítica recorrente à implantação de políticas públicas em nosso país.

Oliveira (2014) afirma que as políticas públicas para a Educação Infantil e a formação continuada de seus profissionais ainda apresentam ranços conceituais dos séculos passados, quando ainda privilegiava a pré-escola em detrimento da creche. Dessa forma, a autora defende que a gestão educacional é de extrema importância na constituição e organização de um sistema municipal de ensino que propicie à sociedade uma educação Infantil de qualidade e aos profissionais as condições de carreira e valorização aliadas ao processo de formação continuada e a condições concretas de trabalho.

Como destaca Kagan (2011), a qualidade da formação das equipes de educação infantil são pré-requisitos para a obtenção de melhores resultados junto a essa fase da educação. Mas o autor ressalta que a formação em serviço de professores "[...] funciona bem se as oportunidades de formação forem sistemáticas, coordenadas, substantivas, bem ministradas" ( $p$. 64). Para isso é importante que se considere a infraestrutura, como regulamentação, financiamento, gestão, certificação profissional, envolvimento da comunidade, vinculação entre os serviços de educação e saúde e, especificamente ligado a formação continuada, "[...] parâmetros e mecanismos de avaliação contínua da formação: especificação de o que as crianças pequenas devem saber e podem fazer junto com capacitação dos professores para coletar essa informação e usá-la para melhorar o ensino das crianças pequenas" (KAGAN, 2011, p. 65).

Nessa perspectiva, encontramos algumas pesquisas voltadas para a investigação de práticas e compreensão dos saberes dos profissionais da creche. Bueno (2007), Zapelini (2007), Guedes (2011), Bragatto (2013), Paulino (2014), Godói (2015), Araújo (2016) e Pereira (2016) concluem em seus trabalhos que há a necessidade de valorização dos saberes daqueles que estão no cotidiano da creche vivenciando os desafios enfrentados e as possibilidades encontradas. Vitta e Emmel (2004, p. 187) ao analisar a prática de profissionais em berçários concluem em relação à formação continuada que

[...] estes programas devem valorizar a prática existente e a partir dela reconhecer as especificidades da educação no berçário. Essa é uma das tarefas mais importantes de educadores $e$ pesquisadores na área de formação de professores.

A ideia da interlocução entre as práticas e saberes das profissionais é tratada por Zapelini (2007) ao discutir as políticas de formação continuada. Guedes (2011) destaca que é necessário saber o que pensam e o que sabem as profissionais da creche, e assim, diminuir a distância entre o mundo acadêmico e o escolar.

A formação continuada é um importante dispositivo para aproximar as práticas das teorias pedagógicas para essa fase educacional. Esse aspecto é defendido por Ferreira e Zurawski (2011) que destacam inclusive visar o desenvolvimento docente. Nesse contexto, segundo as autoras, o coordenador pedagógico tem importante papel na formação, principalmente no que se refere a definir o que é importante que os profissionais saibam para promover a aprendizagem da criança.

O trabalho do coordenador pedagógico e sua função de formador em serviço junto aos profissionais da creche foi discutido nos trabalhos de Zumpano (2010), Leite (2013), Moyano (2014), Bartholomeu (2016) e Fermi (2017). Na leitura, verificamos que apresentam este profissional 
como pessoa de relevância para a formação continuada dos professores de creche, bem como cuidadores e auxiliares, já que acompanha os trabalhos de perto no cotidiano e funciona como mediador em relação a gestão institucional.

Leite (2013) concluiu que, na perspectiva das coordenadoras pedagógicas, a formação continuada ofertada pela Secretaria Municipal de Educação era insuficiente para as necessidades cotidianas da creche. Segundo as coordenadoras entrevistadas, as formadoras que realizavam 0 trabalho, tinham aparentemente pouco conhecimento para assumir tal papel, bem como apresentavam insegurança quando questionadas sobre determinados assuntos por não terem vivências no ambiente da educação infantil, visto que trabalhavam na secretaria de educação. Além disso, algumas coordenadoras não se sentiam contempladas quanto às temáticas trabalhadas nos encontros de formação, já que não eram consultadas para as escolhas do que seria discutido.

Fermi (2017) relata que há a necessidade de não dicotomizar teoria e prática na formação continuada, bem como se trabalhar com o que faz sentido para o grupo, partindo da realidade vivida por essas pessoas. Bartholomeu (2016) evidenciou em sua pesquisa que a documentação pedagógica deve ser uma grande aliada do coordenador pedagógico no processo de formação continuada dos profissionais. Zumpano (2010) afirma que a profissionalização do educador está ligada não só a formação continuada, mas também a sua experiência, com a aprendizagem cotidiana, as interações. Esse processo não acontece individualmente, mas é um caminho trilhado coletivamente.

O maior número de pesquisas realizadas e que fazem parte de nossos achados discutiram aspectos específicos da formação continuada. Santos (2003), Sato (2006), Costa (2006), Boldrin (2007), Borges (2009), Saraiva (2009), Zurawski (2009), Neófiti (2009), Oliveira (2010), Lima (2013), Vieira (2013), Tormin (2014), Chaves (2015), Meinicke (2017), Cacheffo (2017), Pinto (2017) apontam que os programas de formação que acontecem com foco na realidade vivida pelos profissionais tendem a ter melhores resultados, pois muitas discussões emergem das vivências reais de quem atua com as crianças.

Meinicke (2017) ao concluir sua pesquisa, mostra que o planejamento das ações voltadas para a formação continuada não contemplavam as dimensões constitutivas do ser, embora tenham permeado o desenvolvimento das ações.
Também foi constatado que a secretaria na qual ocorreu a pesquisa tem um olhar importante para viabilização e investimento na formação continuada.

Pinto (2017) valoriza o caminho metodológico que buscava priorizar o processo. $\mathrm{Na}$ medida em que os encontros de formação aconteciam, registravam-se os percursos por meio de fotografias, e ao longo do processo, também foram realizadas entrevistas.

A pesquisa buscou
evidenciar possibilidades
de formação em diálogo
com os sentidos e
percepções
profissionais de creche
evidenciando outras
linguagens que passam
pelo campo da teoria,
prática e sensibilização
explorando a reflexão
sobre as práticas no
cotidiano da creche e os
olhares para a infância
(PINTO, 2017, p.116).

Embora constatemos em nossos achados que há certa desvalorização das profissionais que trabalham com bebês e crianças menores de quatro anos, já que na maioria das redes há um foco maior para a pré-escola em detrimento da creche, inclusive no que concerne às políticas $e$ aos programas de formação continuada essa fase da educação começa a ganhar destaque. Moyano (2014) conclui que a creche está avançando a passos lentos e começando a ser vista como escola da infância, assim como seus profissionais sendo entendidos de acordo com suas funções (diretor, professor, monitor, etc.) e não como cuidadores de crianças sem uma definição específica. Esse processo de valorização até o momento está sendo constituído primeiramente no interior das instituições, pelo menos para a maioria dos profissionais.

No entanto, como afirmado por Vitta, Cruz e Scarlassara (2018, p. 71):

[...] se a formação não for uma das prioridades na reorganização da educação básica brasileira, de nada valerão os documentos, com seus indicativos do mínimo de qualidade para toda a população, respeitando todas as diferenças existentes nesse país, pois 
não haverá quem os coloque em prática, quem organize os espaços e tempos, quem selecione e oriente a compra de materiais apropriados, quem interaja e promova a atividade da criança na faixa etária até $1 \mathrm{a} 6 \mathrm{~m}$.

Hoje há um debate urgente sobre as políticas para a primeira infância e como podem ser decisivas para mudanças sociais a longo prazo (ABUCHAIM, 2018; VERCH, 2017).

Vitta e Vitta (2012) mostram ainda, que um trabalho consciente e consistente nessa fase da educação permite a todas as crianças o acesso a atividades que estimulem integralmente todas as áreas do desenvolvimento - sensorial, cognitiva, motora, social, emocional, evitando atrasos desenvolvimentais decorrentes da falta de oportunidades.

Conforme destaca Andrade (2010, p. 175) ao discutir os discursos, legislação e práticas institucionais em educação infantile:

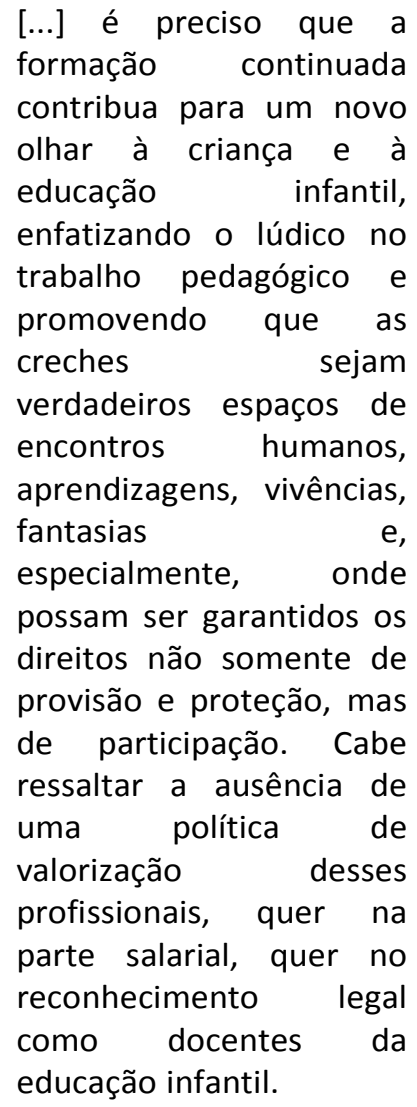

Assim, a formação continuada na creche deve receber atenção, não somente por fazer parte de uma questão legal, mas principalmente pela necessidade de propiciar aos trabalhadores da educação desta primeira etapa da educação, a oportunidade de se desenvolver profissionalmente, e consequentemente, também poder realizar-se como ser humano.

\section{Para não concluir...}

Necessitamos para obter êxito em uma educação de melhor qualidade para as crianças pequenas, dar atenção a todo um conjunto de ações que se entrelaçam: a qualidade dos espaços e recursos físicos e a valorização das pessoas que estão no cotidiano do trabalho no interior das instituições, o que perpassa a remuneração, condições de trabalho, formação continuada e outras vertentes ainda.

Consideramos ao final deste texto, diante do número de trabalhos encontrados, que ainda há muito que investigar no âmbito da formação continuada da creche. A produção científica é uma propulsora para o desenvolvimento e melhoria da qualidade, ou seja, se mais pesquisadores se dedicarem a esse campo de pesquisa, teremos maiores possibilidades de seguir com êxito. Um ponto importante que nos motiva a defender mais pesquisas científicas, é que elas dão visibilidade aos profissionais e ao trabalho exercido nesses espaços.

Esta produção procurou mostrar a importância da formação continuada na creche, destacando que as produções analisadas trouxeram contribuições para avançarmos nesse atendimento educacional. Diante do número de trabalhos encontrados, ainda há muito a ser investigado nesse âmbito; vemos avanços, mas também um longo caminho a percorrer, o que nos motiva a seguir em frente e buscar meios de superar os desafios.

\section{REFERÊNCIAS}

ABUCHAIM, B. O. Panorama das políticas de educação infantil no Brasil. Brasília: UNESCO, 2018.

ANDRADE, L. B. P. Educação infantil: discurso, legislação e práticas institucionais [online]. São Paulo: Editora UNESP: Cultura Acadêmica, 2010, 193p. Disponivel em: <http://books.scielo.org/id/h8pyf> Acesso em: 13 ago 2017.

ARAÚJO, D. A. B. Os espaços lúdicos como elementos formadores em uma creche do município de Santo André. 2016. 131f. Dissertação. (Mestrado em Educação) - Programa de PósGraduação em Gestão e Práticas Educacionais, Universidade Nove de Julho, São Paulo.

BAHIA, C. C.; MOCIUTTI, S. A construção da relação 
creche-família no berçário: contribuição da pesquisa formação. Revista Ibero-Americana de Estudos em Educação, Araraquara, v. 12, n. 1, p. 371-386, 2017. DOI:10.21723/riaee.v12.n1.8646. Disponível em: https://periodicos.fclar.unesp.br/iberoamericana/a rticle/view/8646/6271. Acesso em: 11 set 2016.

BARTHOLOMEU, F. Uma experiência de formação continuada: o papel do coordenador pedagógico e do registro reflexivo na formação de professores de Educação Infantil. 2016. 116f. Dissertação. (Mestrado Profissional em Educação) - Programa de Pós-Graduação em Educação: Formação de Formadores, Pontifícia Universidade Católica de São Paulo, São Paulo.

BRASIL. Lei de Diretrizes e Bases da Educação Nacional - LDBEN. Lei 9394/96, estabelece as diretrizes e bases da educação nacional. Diário Oficial da União.Brasília, DF, 1996.

BRASIL. Ministério da Educação. Plano Nacional de Educação - PNE. Brasília: INEP, 2001.

BRASIL. Ministério da Educação. Lei no 13.005 Plano Nacional de Educação - PNE. Brasília: INEP, $2014 . \quad$ Disponível em: <http://fne.mec.gov.br/images/doc/pne-201420241.pdf>. Acesso em 03 set. 2014.

BOLDRIN, L.; C.; F.A especialização como espaço de formação continuada do professor de educação infantil em Goiás. 2007. Tese. 245f. (Doutorado em Educação) - Programa de Pós-Graduação em Educação, Universidade Federal de Goiás, Goiás.

BORGES, R. R. Curso de extensão universitária PROEPE: contribuição para formação de professores de creche. 2009. Tese. 327f. (Doutorado em Educação) - Programa de PósGraduação em Educação, Faculdade de Educação, Universidade Estadual de Educação, Campinas.

BRAGATTO, A. C. Professoras de crianças de $\mathbf{0}$ a $\mathbf{3}$ anos: dialogando sobre seus percursos formativos. 2013. 325f. Tese. (Doutorado em Educação) Programa de Pós- Graduação em Educação, Universidade Federal de São Carlos, São Carlos.

BUENO, M. C. S. Formação contínua em serviço: um estudo com os profissionais dos centros de educação infantil. 2007. 120f. Dissertação. (Mestrado em Educação Escolar) - Programa de Pós-Graduação em Educação Escolar, Universidade
Estadual Paulista, Araraquara.

CACHEFFO, V. A. F. F. Afetividade na creche: construção colaborativa de saberes e práticas docentes a partir da teoria Walloniana. 2017. $126 f$. Tese. (Doutorado em Educação) - Programa de Pós Graduação em Educação, Faculdade de Ciências e tecnologias, Universidade Estadual Paulista, Presidente Prudente.

CAMPOS, M. M.; FÜLLGRAF, J.; WIGGERS, V. A qualidade da educação infantil brasileira: alguns resultados de pesquisa. Cadernos de Pesquisa, v. 36 , n. 127 , p.87- 128, 2006. DOI: 10.1590/S0100$15742006000100005 . \quad$ Disponível em: http://www.scielo.br/scielo.php?script=sci_arttext \&pid=S0100-15742006000100005\&lng=pt\&tIng=pt. Acesso em: 14 ago 2017.

CHAVES, E. F. A relação entre a formação continuada $e$ as práticas pedagógicas na perspectiva de professoras da educação infantil em um Município do Ceará. 2015. $167 f$. Dissertação. (Mestrado em Educação) - Programa de Pós-Graduação em Educação, Universidade Federal do Ceará, Fortaleza.

COSTA, D. P. L. P. A influência de um programa de formação continuada com vistas a implantação do PROEPRE no desempenho de profissionais de creche assistenciais.2006. 177f. Dissertação. (Mestrado em Educação) - Programa de PósGraduação em Educação, Universidade Estadual de Campinas, Campinas.

FERMI, R. M. B. A atuação de uma coordenadora pedagógica no Centro de Educação Infantil da SME/SP: cantos e saberes que encantam. 2017. 102f. Dissertação. (Mestrado Profissional em Educação) - Programa de Pós-Graduação em Educação: Formação de Formadores, Pontifícia Universidade Católica de São Paulo, São Paulo.

FERREIRA, M. V.; ZURAWSKI, M. P. Formação de professores e currículo integrado. Revista Educação Infantil. Editor Segmento - publicação especial, São Paulo, v.2, p. 30-37, Outubro/2011.

GUEDES, E. A. Formação continuada para professores de Educação Infantil: concepções de profissionais da rede municipal de ensino de Fortaleza. 2011. 150f. Dissertação. (Mestrado em Educação) - Programa de Pós-Graduação em Educação Brasileira, Universidade Federal do Ceará, Fortaleza. 
GODOI, L. Práticas educativas entre pares: estudo do trabalho diário de professoras em um centro de educação infantil paulistano. 2015. $314 f$. Dissertação. (Mestrado em Educação) - Programa de Pós-Graduação em Educação, Universidade de São Paulo, São Paulo.

KAGAN, S. L. Qualidade na educação infantil: revisão de um estudo Brasileiro e recomendações. Cad. Pesqui., São Paulo , v. 41, n. 142, p. 56-67, abr. 2011. DOI: 10.1590/S0100-15742011000100004. Disponível em: http://www.scielo.br/scielo.php?script=sci_arttext \&pid=S0100-15742011000100004\&lng=pt\&tlng=pt. Acesso em: 11 nov 2017.

KRAMER, S. A política do pré-escolar no Brasil: a arte do disfarce. 2.ed. São Paulo: Cortez, 1992.

LEITE, M. I. M. A formação continuada na perspectiva das coordenadoras pedagógicas de creches municipais de Fortaleza.2013. $104 \mathrm{f}$. Dissertação (Mestrado em Educação Brasileira) Programa de Pós-Graduação em Educação Brasileira, Universidade Federal do Ceará, Fortaleza.

LIMA, A. E. O. Formação em contexto na educação infantil: uma parceria em busca da melhoria da qualidade de uma creche municipal de Fortaleza. 2013. 317f. Tese (Doutorado em Educação) Programa de Pós-Graduação em Educação Brasileira, Universidade Federal do Ceará, Fortaleza.

MEINICKE, D. Formação continuada numa perspectiva da educação para a inteireza: uma necessidade do professor de creche. 2017. $185 \mathrm{f}$. Tese (Doutorado em Educação) - Programa de PósGraduação em Educação, Pontifícia Universidade Católica do Rio Grande do Sul, Porto Alegre.

MOYANO, J. A. O coordenador pedagógico e a formação continuada dos profissionais de creche: possibilidades e desafios. 2014. 248f. Dissertação. (Mestrado em Educação) - Programa de PósGraduação em Educação, Universidade Metodista de São Paulo, São Bernardo do Campo.

NEÓFITI, C. C. Educação para a vigilância do desenvolvimento infantil: formação virtual e presencial para educadores de creche. 2009. 188f. Dissertação. (Mestrado em Educação Especial) Programa de Pós-Graduação em Educação Especial, Universidade Federal de São Carlos, São Carlos.
OLIVEIRA, M. N. Impacto do treinamento de educadores de berçários de creches em seus conhecimentos e práticas sobre alimentação. 2010. 110f. Tese (Doutorado em Nutrição) Programa de Pós-Graduação em Nutrição, Universidade Federal de São Paulo, São Paulo.

OLIVEIRA, E. A. A formação continuada das professoras da educação infantil em Anápolis-GO. 2014. 228f. Tese (Doutorado em Educação) Programa de Pós-Graduação em Educação, Pontifícia Universidade Católica de Goiás, Goiânia.

PAULINO, V. B. R. Sentidos que emergem do/circulam no trabalho docente na Educação Infantil. 2014. 208f. Dissertação. (Mestrado em Educação) - Programa de Pós-Graduação em Educação, Universidade Federal do Espírito Santo, Vitória.

PEREIRA, S. A. P. Planejamento e rotina na creche: atuação da equipe gestora e de professoras para mudanças nas práticas educacionais. 2016. 164f. Dissertação. (Mestrado em Educação) - Programa de Pós-Graduação em Gestão e Práticas Educacionais, Universidade Nove de Julho, São Paulo.

PINTO, A. S. Formação continuada na creche: fatos e fotos que revelam um percurso formativo. 2017. 128f. Dissertação (Mestrado em Educação) Programa de Pós- Graduação em Educação, Universidade Federal de São Carlos, Sorocaba.

SANTOS, M. O. V. Contribuições da formação continuada em serviço para a construção da identidade do profissional de educação infantil. 2003. 164f. Dissertação. (Mestrado em Educação) Programa de Pós-Graduação em Educação, Universidade Estadual Paulista, Presidente Prudente.

SANTOS, H. R. A formação continuada do professor de educação infantil: um estudo dos cursos de formação por SME e FABES no município de São Paulo 1989-1996. 2005. 154f. Dissertação. (Mestrado em Educação) - Programa de PósGraduação em Educação, Centro Universitário Nove de Julho, São Paulo.

SANTOS, M. C. O descompasso entre as políticas públicas de formação do professor de educação infantil e a prática cotidiana do município de Bayeux na Paraíba. 2009. 135 f. Dissertação. (Mestrado em Educação) - Programa de Pós- 
Graduação em Educação, Centro de Educação da Universidade Federal da Paraíba, João Pessoa.

SARAIVA, C. F. Educação infantil na perspectiva das relações étnico-raciais: relato de duas experiências de formação continuada de professores no município de Santo André. 2009. 353f. Dissertação. (Mestrado em Educação) Programa de Pós- Graduação em Educação, Pontifícia Universidade Católica de São Paulo, São Paulo.

SATO, T. A. Pesquisa-ação-participativa e a temática sócio-ambiental no processo de formação continuada de professoras da educação infantil. 2006. 114f. Dissertação. (Mestrado em Educação) - Programa de Pós-Graduação em Educação, Universidade Federal de São Carlos, São Carlos.

TORMIN, M. C. Dubabi Du: uma proposta de formação e intervenção musical na creche. 2014. 399f. Tese. (Doutorado em Educação) - Programa de Pós-Graduação da Faculdade de Educação, Universidade de São Paulo, São Paulo.

VERCH, K. Primeira Infância Melhor: transformando a atenção aos primeiros anos de vida na América Latina: desafios e conquistas de uma política pública no sul do Brasil. IDB Monograph (Social Sector. Social Protection and Health Division); IDB-MG- 548, 2017.

VIEIRA, F. R. A formação de professoras em uma creche universitária: o papel da documentação no processo formativo. 2013. 247f. Dissertação. (Mestrado em Educação) - Programa de PósGraduação em Educação, Universidade de São Paulo, São Paulo.

VITTA, F. C. F.; CRUZ, G. A.; SCARLASSARA, B. S. A Base Nacional Comum Curricular e o berçário.Horizontes, [S.I.], v. 36, n. 1, p. 64-73, abr. 2018. ISSN 2317-109X. Disponível em: <https://revistahorizontes.usf.edu.br/horizontes/ar ticle/view/584/260>. Acesso em: 01 jul. 2018. DOI 10.24933/horizontes.v36i1.584.

VITTA, F. C. F.; VITTA, A. Promoção do desenvolvimento da criança no contexto educacional: o berçário. In: ZANIOLO, L. O.; DALL'ACQUA, M. J. C. (Orgs.). Inclusão escolar: Pesquisando políticas públicas, formação de professores e práticas pedagógicas. Jundiaí, Paco Editorial, 2012. p. 141-162.
VITTA, F. C. F.; EMMEL, M. L. G. A dualidade cuidado $x$ educação no cotidiano do berçário. Paidéia, Ribeirão Preto, v. 14, n. 28, 2004.

ZAPELINI, C. A. E. Processos formativos constituídos no interior das instituições de educação infantil. 2007. 176f. Dissertação. (Mestrado em Educação) - Programa de PósGraduação em Educação, Universidade Federal de Santa Catarina, Florianópolis.

ZUMPANO, V. A. A. O coordenador pedagógico e o seu papel na formação continuada em serviço do professor de educação infantil (creche). 2010. 184f. Dissertação. (Mestrado em Educação) Programa de Pós-Graduação em Educação: Psicologia da Educação, Pontifícia Universidade Católica de São Paulo, São Paulo.

ZURAWSKI, M. P. V. Escrever sobre a própria prática: desafios na formação do professor da primeira infância. 2009. 159f. Dissertação. (Mestrado em Educação) - Programa de PósGraduação em Educação, Universidade de São Paulo, São Paulo.

Recebido para avaliação: 11/09/2018

Revisado em: 22/10/2018

Aceite Final: 02/11/2018 